\title{
Spirituality and Gratitude as Predictors of the Quality of Life in
}

\section{Adult Cancer Patients}

\author{
Ms. Alvita de Souza ${ }^{1}$, Dr. Shanmukh V. Kamble ${ }^{2}$
}

\section{ABSTRACT}

The present study was designed to: (a) determine whether there is empirical support for a relationship between Gratitude and Spirituality in Quality of Life, (b) provide an estimate of the strength of this relationship, and (c) examine whether Spirituality and Gratitude is a predictor of quality of life. Stage 1 and Stage 2 Cancer patients were employed for this study. The sample for the study consisted of 397 Cancer patients aged between 36 to 67 years. The Spirituality Scale, Gratitude Scale and the Quality of Life for Adult Cancer Survivors were administered on the participants. Results supported previous research that Spirituality and Gratitude were positively correlated to Quality of life. It was also was a significant predictor in Quality of Life in Cancer Patients. The implication of this study is that Spirituality and Gratitude as a paradigm can be used to improve the Quality of life particularly for those who report very poor health while suffering from Cancer or are at the end of their life with disease

Keywords: Spirituality, Gratitude, Quality of Life, Cancer Patients

Most of the commonly used Quality of Life instruments in oncology do not include spirituality as a core domain. However, previous research suggests that spirituality might be an important aspect of Quality of Life for cancer patients and that it may, in fact, be especially salient in the context of life-threatening illness. This study used a large $(n=1610)$ and ethnically diverse sample to address three questions relevant to including spirituality in Quality of Life measurement: (1) Does spirituality demonstrate a positive association with Quality of Life? (2) Is this association unique?; and (3) Is there clinical utility in including spirituality in Quality of Life measurement? Spirituality, as measured by the Functional Assessment of Chronic Illness Therapy-Spiritual Well-Being (FACIT-Sp), was found to be associated with Quality of Life to the same degree as physical well-being, a domain unquestioned in its importance to Quality of Life. The significant association between Spirituality and Quality of Life was unique, remaining after controlling for core Quality of Life domains as well as other possible confounding variables. Furthermore, spiritual well-being was found to be related to the ability to enjoy life

\footnotetext{
${ }^{1}$ Research Scholar, Karnatak University

${ }^{2}$ Associate Professor, Department of Psychology, Karnatak University

*Responding Author

(C) 2016 I A De Souza, S Kamble; licensee IJIP. This is an Open Access Research distributed under the terms of the Creative Commons Attribution License (http://creativecommons.org/licenses/by/2.0), which permits unrestricted use, distribution, and reproduction in any Medium, provided the original work is properly cited.
} 
even in the midst of symptoms, making this domain a potentially important clinical target. It is concluded that these results support the move to the biopsychosocial spiritual model for Quality of Life measurement in Oncology (Brady et al 1999)

The domain of spirituality is important to understanding quality of life. Spirituality is examined through organizational religious activities, non-organizational activities or as an expression of faith. Spirituality as a variable in the study of quality of life is not a new concept; however, it has returned to the scene during recent years, and has gone through an evolutionary process. (Baker et al,2003)

The relationship between Spirituality and various dimensions of health and Quality of Life has been extensively examined during the past decade. A meta-analysis of studies examining spirituality in relation to quality of life. The meta synthesis of 3,040 published reports was carried out and 51 studies were included in the final analysis. A random effects model of the bivariate correlation between spirituality and quality of life resulted in a moderate effect size ( $r=0.34$, 95\% CI: 0.28-0.40), thereby providing support for the theoretical framework underlying the study wherein Spirituality was depicted as a unique concept that stands in relationship to quality of life. Subsequent regression analyses indicated that differences among operational definitions of spirituality and Quality of Life were associated with the variability in estimates of the magnitude of the relationship $\left(\mathrm{R}^{2}=0.27\right)$ (Sawatsky and Ratner, 2005)

Spirituality is interdependent with the biological, psychological, and interpersonal aspects of life. Research was conducted to determine whether lower Spirituality in men with early stage prostate cancer is associated with worse Quality of life. When two hundred and twenty-two subjects were drawn from a state-funded program providing free prostate cancer treatment to indigent men. It was found that there existed a consistent relationship between Spirituality and Quality of life. Low spirituality was associated with significantly worse physical and mental health, sexual function and more urinary bother after controlling for covariates. All of the psychosocial variables studied reflected worse adjustment in the men with low spirituality. Because the likelihood of prostate cancer survivorship is high, interventions targeting spirituality could impact the physical and psychosocial health of many men (Krupski et al,2006)

The spiritual well being as a core domain in the assessment of Quality of Life in an Australian oncology population. Methods: Four hundred and ninety consecutive cancer patients with mixed diagnoses completed the Functional Assessment of Chronic Illness Therapy--Spiritual WellBeing (FACIT-Sp) Spiritual well being demonstrated a significant, positive association with QOL $(r=0.59)$, A hierarchical multiple regression showed spiritual well being to be a significant, unique contributor to Quality of Life (Whitford et al,2008)

A research was conducted in an international study in 18 countries $(n=5087)$ to observe how Spirituality, Religion and Personal beliefs relate to Quality of life. This research found that 
Spirituality, Religion and Personal beliefs was highly correlated with all of Quality of Life domains ( $p<0.01$ ), although the strongest correlations were found with Psychological and Social domains and overall Quality of Life. When all of the domain scores were entered into a stepwise hierarchal regression analysis, all of the domains contributed to overall Quality of Life $(\mathrm{N}=3636)$, explaining $65 \%$ of the variance. When this was repeated for those people who reported poor health $(\mathrm{N}=588)$, it was found that only four domains explain $52 \%$ of the variance. The first was the level of independence, followed by environment, Spirituality, Religion and Personal beliefs and physical. Gender comparisons showed that despite showing lower scores for facets in the psychological domain, such as negative feelings and poorer cognitions, women still reported greater feelings of spiritual connection and faith than men. Those with less education reported greater faith but were less hopeful. It is suggested that Spirituality, Religion and Personal beliefs should be more routinely addressed in assessment of Quality of Life, as it can make a substantial difference particularly for those who report very poor health or are at the end of their life (WHO 2006). Research conducted on prostrate Cancer patients found that Spirituality was significantly associated with Quality of life. Greater spirituality was associated with better quality of life and psychosocial function (Zavala et al, 2009)

Gratitude is an emotional state and an attitude toward life that is a source of human strength in enhancing one's personal and relational well-being (Emmons et al,2000) Gratitude is a key Psychologial process governing a mindful awareness especially of how one's life is held together through the benevolent actions of others (Mc Cullough et al,2002). Research has shown that gratitude interventions have positive outcomes on measures of well-being. Gratitude listing, behavioral expressions, and grateful contemplation are methods of inducing gratitude. While research has examined gratitude listing and behavioral expressions, no study has tested the longterm effects of a gratitude contemplation intervention on well-being. This study examined the efficacy of a 4-week gratitude contemplation intervention program in improving well-being relative to a memorable events control condition. Pre-test measures of cardiac coherence, trait gratitude, and positive and negative affect were collected. Pre and post-test measures assessing Quality of life and self-esteem were also collected. Daily positive and negative affect were completed twice a week throughout the intervention period. It was found that compared to those in the memorable events condition, participants in the gratitude condition reported higher satisfaction with life and self-esteem. Gratitude as a variable was found to moderate the effects of the gratitude intervention on the quality of life. Grateful contemplation thus can be used to enhance long-term well-being. (Rash et al,2011)

\section{DEFINING THE CONCEPTS}

Spirituality- can be defined as a deep feeling and belief of being connected to a higher spirit. It includes deriving a meaning of life and determining a connection to others along with obtaining a sense of peace. It gives a person an intrinsic worth and this is expressed through engagement in meaningful and purposeful activity (Webster 2012) 
Gratitude-can be defined as the quality or condition of being thankful for being alive, the appreciation of an inclination to return kindness. It refers to thankfulness for the positive as well as the negative circumstances in life.it involves a gratitude to God and gratitude towards human relationships (Mc Cullough and Emmons,2004)

Quality of Life- can be defined as the level of satisfaction that an individual derives from life as a feel good factor despite their health status and the subsequent ability to manage everyday life activities. It involves a positive outlook towards life the psychological wellbeing of an individual. (Salek and Avis,1999)

\section{METHOD}

\section{Sample and Procedure}

The correlation research design was used to investigate the relationship between Spirituality, Gratitude and Quality of life in cancer patients. The sample used for the study consisted of 397 cancer patients from Goa aged between 36-67 years (Male=156 \& Female= 241) The patients were chosen by availability sampling. The inclusion criteria was that the patients should be diagnosed with and be at Stage 1 and Stage 2 of Cancer and should have undergone treatment for the same. All participants received information sheets stating the purpose of the study and signed consent forms prior to participating in the study. The results obtained were analyzed by SPSS 20 and used in the current study.

The researcher utilized 3 sets of standardized Psychological tests for data collection. A) FACIT SP-X Version-4 Webster et al (2003)- this scale asks the cancer patients to mark how their state of mind was within the past 7 days. It has 23 items. Participants indicate their answer from a scale ranging from 0-not at all to 4-Very much. B) The Gratitude-6 by McCullough, M. E., Emmons (2002)- This scale contains 6 specific questions to determine the gratitude amongst individuals. Participants indicate their answer from 1-Strongly disagree to 7- Strongly agree C) The Quality of life for Adult Cancer Survivors- Avis, N. E. Et al (2005)- This scale asks the participants to think about their quality of life after being diagnosed with cancer. It has 47 items. Participants indicate their answer from a scale ranging from 1-Never to 7-Always.

\section{RESULT}

Ha1: There will exist a positive correlation between Spirituality and the Quality of Life in cancer patients

Table 1: Pearson's correlation coefficient among the Spirituality and the Quality of Life in Adult Cancer patients $(\mathrm{N}=397)$

\begin{tabular}{|l|l|l|}
\hline Measures & Spirituality & Quality of Life \\
\hline Spirituality & 1 & $.308^{* *}$ \\
\hline Mean & 52.68 & 252.74 \\
\hline SD & 13.33 & 34.46 \\
\hline
\end{tabular}

**significant at the 0.01 level *significant at the 0.05 level 
The Pearson's coefficient of correlation was computed to measure the relationship between Spirituality and Quality of life in cancer patients. It was found that Spirituality had a significant moderate positive correlation with Quality of life $(\mathrm{r}=.308, \mathrm{p}=<0.01)$. The Mean and SD scores on Spirituality $(M=52.68$ \& $S D=13.33)$ and Quality of Life $(M=252.74 \& S D=34.46)$. thus the hypothesis that there will exist a positive correlation between Spirituality and the Quality of Life in Cancer patients is proved.

Ha2: There will exist a positive correlation between Gratitude and the Quality of life in Cancer patients

Table 2: Pearson's correlation coefficient among the Gratitude and the Quality of Life in Adult Cancer patients $(N=397)$

\begin{tabular}{|l|l|l|}
\hline Measures & Gratitude & Quality of Life \\
\hline Gratitude & 1 & $.376^{*}$ \\
\hline Mean & 32.49 & 252.74 \\
\hline SD & 3.48 & 34.46 \\
\hline
\end{tabular}

**significant at the 0.01 level *significant at the 0.05 level

The Pearson's coefficient of correlation was computed to measure the relationship between Gratitude and Quality of life in cancer patients. It was found that Gratitude had a significant moderate positive correlation with Quality of life $(\mathrm{r}=.376, \mathrm{p}=<0.05)$. The Mean and SD scores on Gratitude ( $M=32.49 \& S D=3.48)$ and Quality of Life $(M=252.74$ \& $S D=34.46)$. Thus the hypothesis that there will exist a positive correlation between Gratitude and the Quality of life in Cancer patients is proved.

Ha3: Spirituality and Gratitude will act as predictors of Quality of Life in cancer patients Table 3: Stepwise multiple regression analysis for predicting the Quality of Life in Cancer patients from Spirituality and Gratitude $(\mathrm{N}=397)$

\begin{tabular}{|l|l|l|l|l|l|l|}
\hline Predictor & $\boldsymbol{\beta}$ & $\mathbf{R}$ & R Square & Adjusted R Square & t value & F \\
\hline 1.Spirituality & 0.167 & & & & $5.62 * *$ & \\
2.Gratitude & 0.084 & .537 & .289 & .280 & $3.64 * *$ & $23.09 * *$ \\
\hline & & & & & & \\
\hline
\end{tabular}

* *significant at the 0.01 level *significant at the 0.05 level

Table 3 showed that stepwise regression revealed a significant model of Quality of Life, $\mathrm{F}=23.09, \mathrm{p}=<.01$, which explained $28 \%$ of the variance (Adjusted $\mathrm{R}^{2}=.28$ ) In the model, the Spirituality $(\beta=0.167) \mathrm{t}=5.62(\mathrm{p}<0.01)$ and Gratitude $(\beta=0.084) \mathrm{t}=3.64(\mathrm{p}<0.01)$ emerged as predictors of the Quality of Life. Thus the hypothesis that Spirituality and Gratitude will act as predictors of Quality of Life in cancer patients is proved. 


\section{DISCUSSION}

The preliminary findings of this study revealed that Spirituality had a significant moderate positive correlation with Quality of $\operatorname{life}(\mathrm{r}=.308, \mathrm{p}=<0.01)$. Gratitude as a variable also had a significant moderate positive correlation with Quality of life $(r=.376, p=<0.05)$. This finding is supported by several research studies. (Watson et al,2003) stated that gratitude has a great impact on the Psychological and subjective well-being of an individual. In individuals suffering from sickness Gratitude was found to moderate the effects when gratitude intervention was interacted with the quality of life. Grateful contemplation thus can be used to enhance long-term well-being. (Rash et al,2011) Gratitude has a variety of empiric connections as established through research to improving quality of life, enhancing personality traits, well-being, psychopathologies, social relations, and coping with sickness (Mc Cullough et al,2013)

The second analysis was carried out with a stepwise multiple regression analysis to find out if the variables of Spirituality and Gratitude predicts quality of life in cancer patients. The variables contributed to $28 \%$ in predicting the Quality of Life which was found to be significant at the 0.051 level $(\mathrm{F}=23.09)$. This finding was supported by a meta-analytic study examining spirituality in relation to quality of life. It indicated a moderate effect size of this correlation. Research by (WHO 2006) conducted a multiple regression on the variable of spirituality along with other variables and found it to be a significant predictor of the quality of life in patients suffering from illness. A multiple regression carried out on the gratitude intervention also indicated this variable to be one of the key factors to improving the quality of life and general wellbeing (Rash et al,2011)

\section{CONCLUSION}

There exists empirical support for a relationship between Gratitude and Spirituality in Quality of life. The current research along with the past empirical data provides an estimate moderate of the strength of the relationship of Spirituality and Gratitude in relation to Quality of Life in Cancer patients. Through multiple regression analysis it reinforces the research that Spirituality and Gratitude were significant predictors of Quality of Life.

\section{REFERENCES}

Baker, D. C. (2003). Studies of the inner life: the impact of spirituality on quality of life. Quality of Life Research: An International Journal of Quality of Life Aspects of Treatment, Care and Rehabilitation, 12 Suppl 1, 51-7. Retrieved from http://www.ncbi.nlm.nih.gov/pubmed/12803311

Bartlett, S. J., Piedmont, R., Bilderback, A., Matsumoto, A. K., \& Bathon, J. M. (2003). Spirituality, well-being, and quality of life in people with rheumatoid arthritis. Arthritis and Rheumatism, 49(6), 778-783. http://doi.org/10.1002/art.11456

Brady, M. J., Peterman, a H., Fitchett, G., Mo, M., \& Cella, D. (1999). A case for including spirituality in quality of life measurement in oncology. Psycho-Oncology, 8(5), 417-428. http://doi.org/10.1002/(SICI)1099-1611(199909/10)8:5<417::AID-PON398>3.0.CO;2-4 


\section{Spirituality and Gratitude as Predictors of the Quality of Life in Adult Cancer Patients}

Daaleman, T. P. (2004). The Spirituality Index of Well-Being: A New Instrument for HealthRelated Quality-of-Life Research. The Annals of Family Medicine, 2(5), 499-503. http://doi.org/10.1370/afm.89

Davison, S. N., \& Jhangri, G. S. (2010). Existential and religious dimensions of spirituality and their relationship with health-related quality of life in chronic kidney disease. Clinical Journal of the American Society of Nephrology, 5(11), 1969-1976. http://doi.org/10.2215/CJN.01890310

Giovagnoli, A. R., Meneses, R. F., \& da Silva, A. M. (2006). The contribution of spirituality to quality of life in focal epilepsy. Epilepsy \& Behavior: E\&B, 9(1), 133-9. http://doi.org/10.1016/j.yebeh.2006.04.002

Greeson, J. M., Webber, D. M., Smoski, M. J., Brantley, J. G., Ekblad, A. G., Suarez, E. C., \& Wolever, R. Q. (2011). Changes in spirituality partly explain health-related quality of life outcomes after Mindfulness-Based Stress Reduction. Journal of Behavioral Medicine, 34, 508-518. http://doi.org/10.1007/s10865-011-9332-x

Hsien-Chuan Hsu, P., Krägeloh, C. U., Shepherd, D., \& Billington, R. (2009). Religion/spirituality and quality of life of international tertiary students in New Zealand: an exploratory study. Mental Health, Religion \& Culture, 12(4), 385-399. http://doi.org/10.1080/13674670902752920

Katsuno, T. (2003). Personal Spirituality of Persons with Early-Stage Dementia: Is it Related to Perceived Quality of Life? Dementia, 2(3), 315-335. http://doi.org/10.1177/14713012030023003

Koenig, H. G. (2008). Concerns about measuring “spirituality” in research. The Journal of Nervous and Mental Disease, 196(5), 349-355. http://doi.org/10.1097/NMD.0b013e31816ff796

Konopack, J. F., \& McAuley, E. (2012). Efficacy-mediated effects of spirituality and physical activity on quality of life: A path analysis. Health and Quality of Life Outcomes. http://doi.org/10.1186/1477-7525-10-57

Krupski, T. L., Kwan, L., Fink, A., Sonn, G. A., Maliski, S., \& Litwin, M. S. (2006). Spirituality influences health related quality of life in men with prostate cancer. Psycho-Oncology, 15(2), 121-131. http://doi.org/10.1002/pon.929

McCullough, M. E. (2002). Savoring Life , Past and Present: Explaining What Hope and Gratitude Share in Common. Psychological Inquiry, 13(4), 302-304. http://doi.org/10.2307/1448873

MCCUllOUGH, M., \& EMMONS, R. A. (2013). The Psychology of Gratitude. Mentálhigiéné és Pszichoszomatika (Vol. 14). http://doi.org/10.1556/Mental.14.2013.2.3

Mytko, J. J., \& Knight, S. J. (1999). Body, mind and spirit: towards the integration of religiosity and spirituality in cancer quality of life research. Psycho-Oncology, 8(5), 439-450. http://doi.org/10.1002/(SICI)1099-1611(199909/10)8:5<439::AID-PON421>3.0.CO;2-L

Sawatzky, R., Ratner, P. a., \& Chiu, L. (2005). A meta-analysis of the relationship between spirituality and quality of life. Social Indicators Research, 72, 153-188. http://doi.org/10.1007/s11205-004-5577-x 
Tate, D. G., \& Forchheimer, M. (2002). Quality of life, life satisfaction, and spirituality: comparing outcomes between rehabilitation and cancer patients. American Journal of Physical Medicine \& Rehabilitation / Association of Academic Physiatrists, 81(6), 400410. http://doi.org/00002060-200206000-00002 [pii]

Watkins, P. C., Woodward, K., Stone, T., \& Kolts, R. L. (2003). Gratitude and Happiness: Development of a Measure of Gratitude, and Relationships With Subjective Well-Being. Social Behavior and Personality: An International Journal. http://doi.org/10.2224/sbp.2003.31.5.431

Whitford, H. S., Olver, I. N., \& Peterson, M. J. (2008). Spirituality as a core domain in the assessment of quality of life in oncology. Psycho-Oncology, 17(11), 1121-1128. http://doi.org/10.1002/pon.1322

WHOQoL SRPB Group. (2006). A cross-cultural study of spirituality, religion, and personal beliefs as components of quality of life. Social Science and Medicine, 62(6), 1486-1497. http://doi.org/10.1016/j.socscimed.2005.08.001

Zavala, M. W., Maliski, S. L., Kwan, L., Fink, A., \& Litwin, M. S. (2009). Spirituality and quality of life in low-income men with metastatic prostate cancer. Psycho-Oncology, 18(7), 753-761. http://doi.org/10.1002/pon.1460 